Revista Científica do Corpo de Bombeiros Militar de Pernambuco

XVIII Seminário Nacional de Bombeiros - Foz do Iguaçu PR

Vol.04 No11 - Edição Especial XVIII SENABOM - ISSN 2359-4829

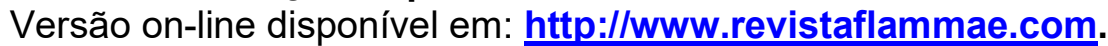

\title{
VIABILIDADE PARA UTILIZAÇÃO DO MÉTODO DE GRETENER PARA A ANÁLISE DE RISCO DE INCÊNDIO EM EDIFICAÇÕES
}

\author{
FEASIBILITY FOR THE USE OF THE GRETENER METHOD FOR FIRE RISK \\ ANALYSIS IN BUILDINGS
}

Fernando Raimundo Schunig ${ }^{1}$

\section{Resumo}

A avaliação do risco de incêndio, além de ser uma exigência legal em vários estados do Brasil, é de importância fulcral para engenheiros civis, técnicos de segurança, profissionais do Corpo de Bombeiros e seguradoras, pois se trata de uma ferramenta quantitativa que permite uma melhor avaliação do risco de Incêndio. O objetivo deste artigo é mostrar o método desenvolvido pro Gretener para a avaliação de risco de incêndio e analisar a sua viabilidade para utilização no Corpo de Bombeiros. Trata-se de uma pesquisa bibliográfica, e para o desenvolvimento deste artigo, foi utilizado como referencial bibliográfico para o método original de Gretener. Como resultado, para a utilização do Método de Gretener, é necessário a adequação de alguns termos e conteúdos de forma a atender a legislação local, de forma a não comprometer $\mathrm{o}$ resultado.

Palavras-chave: Análise de Risco. Incêndio. Gretener.

\begin{abstract}
The fireriskassessment, in addition to being a legal requirement in several Brazilian states, is of paramount importance for civil engineers, safety technicians, Fire Department professionals and insurers, since it is a quantitative tool that allows a better assessment of the risk of fire. The objective of this article is to show the method developed by Gretener for the fire risk assessment and to analyze its feasibility for use in the Fire Department. This is a bibliographical research, and for the development of this article, was used as bibliographical reference for the original method of Gretener. As a result, for the use of the Gretener Method, it is necessary to adapt some terms and content in order to comply with local legislation, so as not to compromise the result.
\end{abstract}

Keywords: Risk analysis. Fire. Gretener.

1. Oficial do Corpo de Bombeiros do Estado do Paraná (1990), mestre em Educação, Estado e Políticas Sociais pela UNIOESTE (2015), licenciado em Matemática pela UFTPR (2000), licenciado em Física pela ULBRA (2015), Pós Graduado em Engenharia de Segurança Contra Incêndio e Pânico pela PUC-PR (2010). Cascavel, PR; fernando.schunig@gmail.com. 


\section{INTRODUÇÃO}

Em 1960, o engenheiro Max Gretener, diretor da Associação de Proteção Contra Incêndio da Suíça, iniciou estudos sobre o cálculo do risco de incêndio em indústrias e grandes edifícios. Seu método, publicado em 1965, visava atender às necessidades das companhias de seguro. Em 1968, o Corpo de Bombeiros suíço propôs adotar esse mesmo método, também, para avaliar os meios de proteção contra incêndio das edificações (SIA, 2004).

Em 1984, a SocietéSuissedesIngénieurs et dês Architectes (SIA) publicou o documento SIA-81 (2004), "Método de avaliação de risco de incêndio", tendo por base os trabalhos de Gretener, revisado por um grupo de especialistas das companhias de seguro privadas e estatais e da SIA. Esse grupo adaptou o método ao atual conhecimento e experiência suíços e internacionais. Segundo Cajot et al. (s.d.), os resultados desse trabalho são demonstráveis cientificamente, apesar de nem todos terem sido demonstrados.

O método Gretener também serviu de base para as normas austríacas, publicadas pela Liga Federal de Combate a Incêndio da Áustria em 1987. Os valores das cargas de incêndio específicas desse método também são aceitos na Nova Zelândia e serviram de base para a NBR 14432:2000. Em dezembro de 1996, o SIA-81 revisou e atualizou o método. O método de Gretener talvez seja o mais difundido método quantitativo de avaliação de risco. (SCHUNIG, 2016).

De acordo com Almeida e Ferreira (2008), as técnicas quantitativas se baseiam na quantificação e identificação dos riscos associados ao seu impacto, estimando a probabilidade da sua ocorrência.

No Brasil, a NBR 14432:2000, que trata das exigências de resistência ao fogode elementos construtivos deedificações permite o emprego do método de Gretener, desde que adequado à realidade brasileira, pois como foi atualizado na década de 80 , muitos dos seus parâmetros já não estão adequados a utilização, como por exemplo, o volume 
de água do reservatório, que na época da atualização era exigido um volume grande e atualmente com a modernização de bombas e equipamentos mais eficientes, conseguese melhores resultados com um consumo menor de água, não sendo mais necessário grandes volumes de água para o combate a incêndios.

5.5 Admite-se a utilização de métodos tendo por base a contraposição de medidas de proteção contra incêndio para a determinação dos tempos requeridos de resistência ao fogo dos elementos construtivos. Estes tempos podem variar em função da quantificação do risco e da adoção de medidas complementares de proteção ativa e de proteção passiva. Em particular, entre esses métodos, pode ser adotado o método de Gretener ou seus sucedâneos. (NBR 14432, 2000)

O método de Gretener adaptado já vem sendo aplicado, mesmo que parcialmente no Estado de Minas Gerais, na Instrução Técnica 35, em seu anexo B:

B.1.3 O Coeficiente de Segurança contra incêndio da edificação $(\gamma)$ será obtido adotando a razão entre o Fator de Segurança $(S)$ e Risco Global de Incêndio $(R)$ previstos na edificação, pela seguinte equação: $\gamma=\frac{\Sigma}{z}$

B.1.3.1 O Coeficiente de Segurança Mínimo Aceitável $\left(\gamma_{\min }\right)$ visa balancear medidas facilitadoras e medidas inibidoras de um possível incêndio. Sendo considerada uma edificação ou conjunto de edificações seguras para os propósitos desta Instrução Técnica quando $\gamma \geq \gamma_{\min }$.

B.1.3.2 Para dispensa de medidas de segurança contra incêndio e pânico previstas no anexo "A" ou avaliação de risco para projeção de outras medidas diferentes daquelas constantes no referido anexo, o RT deverá apresentar para a edificação um coeficiente de segurança mínimo, $\gamma_{\min }=1$, proporcionado por medidas de segurança passivas já existentes na edificação, pelo risco de incêndio devido as características e uso da edificação, além da projeção de medidas de segurança obrigatórias previstas no item 6.2.2.2 desta IT. (IT 35, 2017)

A avaliação do risco de incêndio, além de ser uma exigência legal em vários estados do Brasil, é de importância fulcral para engenheiros civis, técnicos de segurança, profissionais do Corpo de Bombeiros e seguradoras, pois se trata de uma ferramenta quantitativa que permite uma melhor avaliação do risco de incêndio.

Em sua dissertação, Schunig (2016) relata que:

Para a prevenção contra incêndio e pânico, faz-se necessário inicialmente a identificação das ameaças existentes na edificação, que pode ser feita por meio de uma análise de riscos. Com o risco conhecido e determinado, em um segundo momento é possível, face aos riscos existentes, a adoção de medidas mitigadoras e redutoras de riscos, que de maneira geral, atuam sobre os perigos existentes na edificação. 
$\mathrm{Na}$ prevenção contra incêndios e pânicos, trabalha-se com riscos admissíveis e se propõe medidas para a redução destes. Para que os resultados sejam efetivos, faz-se necessário um entendimento mais abrangente.

Assim, não resta dúvida que uma análise de risco realizada com a utilização de critérios específicos para o incêndio, pode facilitar a adoção de medidas mitigadores e redutoras de riscos e perigos.

O objetivo deste artigo é mostrar a método desenvolvido pro Gretener para a avaliação de risco de incêndio e analisar a sua viabilidade para utilizar no Corpo de Bombeiros. Trata-se de uma pesquisabibliográfica, que segundo Lakatos (2010, p.171), refere-se ao levantamento, seleção e documentação de bibliografias já publicada sobre o assunto que está sendo pesquisado em livros, revistas, jornal, boletins, monografias, teses, dissertações, material cartográfico, com o objetivo de colocar o pesquisador em contato direto com o material escrito sobre o tema.

Para o desenvolvimento deste artigo, foi utilizado como referencial bibliográfico para o método original de Gretener na publicação contida em SIA (1984).

\section{DESENVOLVIMENTO}

O entendimento do método é fundamental para que se possa avaliar a sua aplicação junto ao Corpo de Bombeiros. Assim, será apresentado uma síntese do método, identificação dos fatores e variáveis aplicáveis, de forma a poder ao final obter o índice de segurança da edificação e quantificar se apresenta ou não condições de segurança contra incêndio.

\section{Fórmula Base}

O fator de exposição ao perigo de incêndio $\mathrm{B}$ é definido como o produto de todos os fatores de perigo "P", dividido pelo produto de todas as medidas de proteção "M". 
Revista Científica do Corpo de Bombeiros Militar de Pernambuco

XVIII Seminário Nacional de Bombeiros - Foz do Iguaçu PR

Vol.04 N011 - Edição Especial XVIII SENABOM - ISSN 2359-4829

Versão on-line disponível em: http://www.revistaflammae.com.

$$
B=\frac{P}{M}
$$

As medidas de proteção "M" estão divididas em três grandes grupos: medidas normais "N", especiais "S" e construtivas "F".

Os perigos são expressos pelos seguintes fatores:

I) Perigos associados ao conteúdo: móveis e equipamentos que contribuem para o desenvolvimento de um incêndio (carga de incêndio), fatores de dificultam a evacuação de pessoas no caso de incêndio e ainda também os fatores de emissão de fumação e ação corrosiva.

São fatores de perigo associados ao conteúdo:

- q: fator referente à carga de incêndio mobiliária;

- c: fator referente à combustibilidade da carga de incêndio;

- r: fator referente à produção de fumaça pelos materiais combustíveis;

- $\mathrm{k}$ : fator referente à toxicidade e corrosividade dos gases do incêndio;

II) Perigos associados a edificação: são resultantes da forma de construção: estrutura, pavimentos, fachada, etc., assim como fatores associados ao nível do andar. São fatores de perifo associados a edificação:

- i: fator referente à carga de incêndio imobiliária;

- e: fator referente à altura do andar do compartimento considerado;

- g: fator referente à área do compartimento e às relações de largura e comprimento desta área.

$$
B=\frac{P}{M}=\frac{(k \cdot c \cdot r \cdot k) \cdot(\text { i.e.g } g)}{N \cdot S \cdot F}
$$

Onde:

- B: Fator de exposição ao perigo;

- P: Perigo Potencial; 
Revista Científica do Corpo de Bombeiros Militar de Pernambuco

XVIII Seminário Nacional de Bombeiros - Foz do Iguaçu PR

Vol.04 No11 - Edição Especial XVIII SENABOM - ISSN 2359-4829

Versão on-line disponível em: http://www.revistaflammae.com.

O Quadro 1 apresenta o resumo das medidas de segurança (M) para o Método de Gretener, de forma a facilitar a seu entendimento e amplitude das medidas na segurança contra incêndio.

Quadro 1 - Medidas de Segurança (M)

\begin{tabular}{|c|l|}
\hline Medida de Segurança & Especificação da medida \\
\hline $\mathrm{N}$ & Medidas normais \\
\hline $\mathrm{S}$ & Medidas especiais \\
\hline $\mathrm{F}$ & Medidas construtivas \\
\hline
\end{tabular}

Fonte: $\mathrm{O}$ autor

O Quadro 2 apresenta o resumo dos fatores de perigo, assim como sua relação de perigo quanto ao conteúdo e também a edificação. Esses fatores considerados são de extrema importância para que possamos avaliar o risco, pois leva em consideração fatores que atualmente a legislação vigente não contempla.

Quadro 2 - Fatores de Perigo

\begin{tabular}{|c|l|c|}
\hline Fator de Perigo (P) & Especificação dos perigos & Relação de Perigo \\
\hline $\mathrm{q}$ & Carga de incêndio mobiliária & \\
$\mathrm{c}$ & Combustibilidade & Conteúdo \\
$\mathrm{r}$ & Produção de fumaça & \\
$\mathrm{k}$ & Toxidade e corrosividade & \\
\hline $\mathrm{i}$ & Carga de incêndio imobiliária & \\
$\mathrm{e}$ & Altura do andar & Edificação \\
$\mathrm{g}$ & Relação largura x área & \\
\hline
\end{tabular}

Fonte: $\mathrm{O}$ autor

Para obtermos o risco efetivo de incêndio na edificação, multiplica-se o fator de perigo "B" a um fator de perigo de ativação "A", possibilitando assim que seja quantificado de acordo com a metodologia proposta por Gretener a quantificação por 
um índice que indica a possibilidade de ocorrência de um incêndio. Na prática é definido por:

- Avaliação das fontes de ignição, cuja carga de incêndio é favorável ao desenvolvimento do processo de incêndio;

- Característica da inflamabilidade dos materiais existentes na edificação.

$$
R=B \cdot A=\frac{P}{N \cdot S \cdot F} \cdot A
$$

De acordo com Macedo (2008), o risco de efetivo de incêndio é calculado para o maior compartimento de incêndio ou o mais perigoso de um edifício.

O Perigo de Ativação esta associado fontes de calor térmica, elétrica, mecânica e química, assim como a outros fatores de origem amtropológica: manutenção, falta de treinamento, etc.

\section{Medidas de Proteção}

Para a determinação das medidas de proteção, no cálculo do Método Gretener, efetua-se passo a passo, definindo os fatores de influência de cada medidas de proteção para cada um dos compartimentos de incêndio em estudo. As medidas de segurança são divididas em três grupos básico: fatores básicos $(\mathrm{N})$, sistemas especiais $(\mathrm{S})$ e proteção contra incêndios $(\mathrm{F})$.

Fatores Básicos: grupo "N"

As medidas normais de proteção são um conjunto de medidas que se consideram necessárias para qualquer tipo de edifício, independentemente do seu uso ou ocupação, sendo que sua falta ou não conformidade com os critérios definidos constitui uma penalização, agravando o risco de incêndio. A existência de acordo com os requisitos do método deverá ser considerada neutra, ou seja, não agrava o risco, mas 
Revista Científica do Corpo de Bombeiros Militar de Pernambuco

XVIII Seminário Nacional de Bombeiros - Foz do Iguaçu PR

Vol.04 N011 - Edição Especial XVIII SENABOM - ISSN 2359-4829

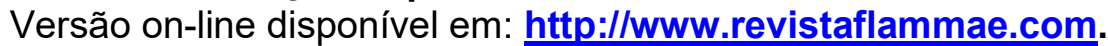

também não é fator de bonificação. $\mathrm{O}$ grupo "N" é constituído por 5 fatores básicos de segurança contra incêndio, conforme a expressão:

$\mathrm{N}=\prod_{5}^{1} n_{i}$, onde:

- $\mathrm{n} 1$ : Proteção móvel por extintores $(1 \leq \mathrm{n} 1 \leq 0,9)$;

- n2: Proteção fixa com hidrantes internos $(1 \leq \mathrm{n} 2 \leq 0,8)$;;

- n3: Confiabilidade do abastecimento e suprimento de água; $(0,5 \leq \mathrm{n} 3 \leq 1)$;

- n4: Distância entre o hidrante externo e a entrada da edificação $(1 \leq \mathrm{n} 4 \leq 0,9)$;

- n5: Pessoal treinado no uso dos equipamentos $(1 \leq \mathrm{n} 5 \leq 0,8)$;

Sistemas especiais: grupo "S"

As medidas especiais de proteção constituem um conjunto de medidas que não são exigíveis em todos os tipos de edifícios. Assim, a sua inexistência ou não conformidade com os requisitos mínimos definidos pelo método não deverá agravar o risco de incêndio, devendo ser consideradas neutras para o processo de cálculo. Ao contrário, a existência de medidas deste tipo de acordo com as exigências do método constitui uma bonificação, já que sua implementação reduz o risco de incêndio.

$\mathrm{O}$ grupo "S" é constituído por 6 fatores que são sistemas "especiais" de segurança contra incêndio, conforme a expressão:

$\mathrm{S}=\prod_{6}^{1} s_{i}$, onde:

- s1: modo de detecção do incêndio $(1,45 \leq \mathrm{s} 1 \leq 1)$;

- $\quad$ s2: modo de transmissão do alarme $(1,2 \leq \mathrm{s} 2 \leq 1)$;

- $\mathrm{s} 3$ : tipo de brigada e tipo do bombeiro da localidade $(1,9 \leq \mathrm{s} 3 \leq 1)$;

- s4: tempo resposta do Corpo de Bombeiros, tipo de brigada e chuveiros automáticos $(1 \leq \mathrm{s} 4 \leq 0,6)$; 
Revista Científica do Corpo de Bombeiros Militar de Pernambuco

XVIII Seminário Nacional de Bombeiros - Foz do Iguaçu PR

Vol.04 N011 - Edição Especial XVIII SENABOM - ISSN 2359-4829

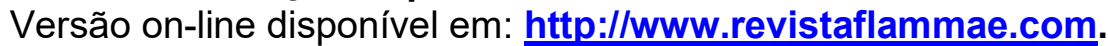

- s5: sistemas automáticos de extinção $(2 \leq \mathrm{s} 5 \leq 1)$;

- s6: sistema de exaustão de fumaça e calor $(1,2 \leq \mathrm{s} 6 \leq 1)$.

Proteção contra incêndios: grupo "F"

A medida de proteção contra incêndio mais eficaz consiste numa concepção bem estudada da edificação do ponto de vista da técnica de proteção contra incêndio. $O$ perigo de propagação de um incêndio pode, em grande escala, ser consideravelmente limitado graças à escolha de certos materiais resistente ao fogo, bem como da utilização de medidas apropriadas, como a compartimentação, isolamento de risco, etc.

O grupo "F" é constituído por 4 fatores de proteção contra incêndios referentes à construção, conforme a expressão:

$\mathrm{F}=\prod_{\frac{1}{4}}^{1} f_{i}$, onde:

- $\mathrm{fl}$ : está associado à resistência ao fogo das estruturas $(1,3 \leq \mathrm{fl} \leq 1)$;

- f2: refere-se à resistência ao fogo da fachada $(1,5 \leq \mathrm{f} 2 \leq 1)$;

- f3: refere-se à resistência ao fogo dos elementos de vedação horizontal $(1,2 \leq \mathrm{f} 3$ $\leq 1)$;

- f4: relaciona o tamanho das células $(1,4 \leq \mathrm{f} 4 \leq 1)$.

\section{Fatores de Perigo $\left(\mathbf{R}_{\mathbf{n}}\right)$}

Para a determinação dos fatores de perigo $\left(\mathrm{R}_{\mathrm{n}}\right)$, semelhante ao procedimento efetuado para as medidas de proteção, o cálculo do Método GRETENER efetua-se passo a passo, definindo os fatores de influência do perigo para cada um dos compartimentos de incêndio em estudo. São utilizados os fatores: q (carga de incêndio), $\mathrm{c}$ (combustibilidade $\mathrm{e}$ inflamabilidade), $\mathrm{r}$ (enfumaçamento), $\mathrm{k}$ (toxidade $\mathrm{e}$ 
corrosividade), i (carga de incêndio imobiliária), e (nível do andar) e g (amplitude do compartimento).

- q - é um fator associado à carga de incêndio mobiliaria, corresponde ao valor da quantidade calor desenvolvida no incêndio devido aos móveis e equipamentos, dividido pela área ocupada, expressa em $\mathrm{MJ} / \mathrm{m}^{2}(2,5 \leq \mathrm{q} \leq 0,6)$;

- c - é um fator associado à combustibilidade da carga de incêndio, quantifica a inflamabilidade e velocidade da combustão $(1,6 \leq \mathrm{c} \leq 1)$;

- $\mathrm{r}$ - é um fator associado ao enfumaçamento causado pela carga de incêndio, quantifica materiais que liberam fumaça mais intensa $(1,2 \leq \mathrm{r} \leq 1)$;

- $\mathrm{k}$ - é um fator associado à toxicidade e corrosividade dos gases, quantifica matérias que liberam gases tóxicos e corrosivos durante o processo de queima $(1,2 \leq \mathrm{k} \leq 1)$.

- i - Carga de Incêndio Imobiliária, define a parte combustível da edificação contida nas estruturas, pavimentos e fachadas, e sua influência sobre a propagação do incêndio. Este fator depende da combustibilidade da estrutura resistente e dos elementos não resistentes da fachada, bem como das camadas de isolamento combustível dos pisos $(1,3 \leq \mathrm{i} \leq 1)$.

- e - Nível do Andar ou altura local, no caso de edifícios de vários andares, este fator quantifica, em função da situação dos andares, as dificuldades de fuga das pessoas que ocupam a edificação e da ação do Corpo de Bombeiros $(3 \leq \mathrm{e} \leq 1)$.

- g - Amplitude dos compartimentos de incêndio, este fator quantifica a probabilidade de propagação horizontal e vertical do incêndio. Quanto maior as dimensões da edificação, mais desfavorável se tornam as condições para o combate a incêndios. A relação comprimento/largura das edificações influencia circunstancialmente nas possibilidades de acesso pelo Corpo de Bombeiros $(5 \leq$ $\mathrm{g} \leq 0,4)$.

\section{Risco Admissível $\left(\mathbf{R}_{\mathrm{u}}\right)$}


O risco admissível será determinado para cada tipo de edificação especificamente, pois sabemos que o risco é composto de uma série de fatores.

Para Macedo (2008, p. 23), “[...] o risco admissível deve ser definido caso a caso, não se utilizando o mesmo valor para todos os tipos de edifícios".

O método de Gretener recomenda partindo-se do risco normal, corrigi-lo com um fator $\left(\mathrm{P}_{\mathrm{HE}}\right)$ que quantifica a existência de fatores que possam dificultar a evacuação dos ocupantes.

$\boldsymbol{R}_{u}=\boldsymbol{R}_{n} \cdot \boldsymbol{P}_{H E}$

Onde:

- $\quad \mathrm{P}_{\mathrm{HE}}=1,3$ para risco de incêndio normal;

- $\quad \mathrm{P}_{\mathrm{HE}}<1$ para um número elevado de pessoas ou uma edificação muito alta;

- $\quad \mathrm{P}_{\mathrm{HE}}>1$ em casos esporádicos, onde a evacuação das pessoas possa ocorrer sem qualquer tipo de dificuldade;

- $\mathrm{P}_{\mathrm{HE}}=1$ quando não é verificado situações agravantes para a evacuação de pessoas.

Em geral, os perigos são acrescidos nos casos de hotéis, grandes edifícios, teatros museus, cinemas, hospitais, shopping center, etc. e os perigos são reduzidos são as edificações geralmente não acessíveis ao público em geral, ocupados por um número restrito de pessoas que conhecem bem o local, como por exemplo armazéns e silos. 


\section{Prova da Segurança Contra Incêndio}

A prova da segurança contra incêndio é obtida quando comparamos o risco de perigo $(\mathrm{Rn})$ com o risco admissível $(\mathrm{Ru})$.

Para que tenhamos uma edificação com proteção contra incêndio suficiente, o risco de perigo $(\mathrm{Rn})$ não pode ser maior que o risco admissível $(\mathrm{Ru})$, portanto:

$$
R_{u} \geq R_{n}
$$

Assim, desta condição podemos definir um índice " $\gamma$ "para a condição mínima de segurança contra incêndio.

$$
Y=\frac{\boldsymbol{R}_{u}}{\boldsymbol{R}_{n}} \geq \mathbf{1}
$$

Onde $\gamma=$ índice do risco de Incêndio, sendo que se $\gamma<1$, a edificação não apresenta condições suficientes de segurança contra incêndio; se $\gamma \geq 1$ a edificação apresenta condições suficientes de segurança contra incêndio.

\section{CONCLUSÕES}

A identificação dos riscos de incêndio em uma edificação é fundamental para que possamos dimensionar medidas de proteção adequadas, de modo a não exigirmos em excesso ou falta de medidas.

Um dos aspectos interessantes do método de Gretener é que ele considera características que, de modo geral, a legislação brasileira não leva em conta. Por exemplo: existência ou não de Corpos de Bombeiros, que edificações idênticas devem ser tratadas de modo diferente caso uma esteja em uma cidade com Corpo de Bombeiros e a outra não, ou no caso de uma estar próxima a um Posto de Bombeiros e a outra distante (tempo resposta do Corpo de Bombeiros); modos de detecção do incêndio e de 
Revista Científica do Corpo de Bombeiros Militar de Pernambuco

XVIII Seminário Nacional de Bombeiros - Foz do Iguaçu PR

Vol.04 No11 - Edição Especial XVIII SENABOM - ISSN 2359-4829

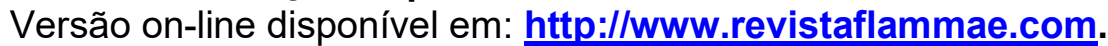

transmissão do aviso; área de ventilação de um recinto; relação largura / comprimento da área em análise; toxicidade e corrosividade da fumaça

Para a determinação dos fatores de risco associados à carga de incêndio mobiliária, no método original é proposta uma tabela para cargas de incêndio mobiliárias e fatores de influência para os diversos usos, que pode perfeitamente ser utilizada com as normas atuais e auxilia bastante o processo de obtenção do risco de incêndio.

Uma análise de risco de incêndio mais simplificada agiliza o processo de análise dos Planos de Segurança Contra Incêndio e Pânico, dando mais celeridade e confiança, principalmente por ser o método de Gretener uma análise quantitativa que leva em conta fatores de perigo essenciais, permitindo definir e avaliar medidas em termos de eficácia.

A utilização do índice obtido pela metodologia proposta pode ser utilizado como um indicador para segurança em edificações, pois quantifica o risco existente, serve de referência para o estabelecimento das medidas preventivas necessárias e mitigadoras de redução de risco.

Para a utilização do Método de Gretener, é necessário a adequação de alguns termos e conteúdos de forma a atender a legislação local, pois como é uma metodologia desenvolvida na década de 60 muitos termos e valores referenciais precisam ser corrigidos, de tal forma a não perder os referenciais máximos e mínimos, mantendo-se assim a proporção e o peso de cada valor em relação ao método original, de forma a não comprometer o resultado.

\section{REFERÊNCIAS}

ALMEIDA. Eliezer Pedrosa de. FERREIRA. Miguel Luis Ribeiro. Técnicas de análise de risco aplicadas à planejamento e programação de projetos da construção civil. IV Congresso Nacional de Excelência em Gestão. Niterói. RJ. 2008

IT 35. Instrução Técnica n ${ }^{\circ} 35 / 2017$ - $2^{a}$ Edição. Segurança contra incêndio em edificações que compõem o patrimônio cultural. Corpo de Bombeiros Militar de Minas Gerais. Disponível no site: 
Revista Científica do Corpo de Bombeiros Militar de Pernambuco XVIII Seminário Nacional de Bombeiros - Foz do Iguaçu PR Vol.04 No11 - Edição Especial XVIII SENABOM - ISSN 2359-4829

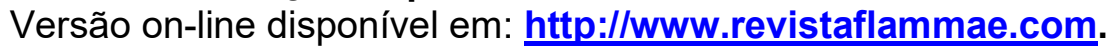

http://www.bombeiros.mt.gov.br/arquivos/File/NORMAS/IT35CBMMG.pdf. Acesso em 22 ago 18 às $16: 15 \mathrm{~h}$

LAKATOS, E. M.; MARCONI, M. A.. Pesquisa. In: Paulo: Atlas, 2010. cap. 8, p. 139-155.

MACEDO. Mario José de Magalhães. Método de Gretener. Ed. VerlagDashöfer. Portugal. 2008. ISBN 978.989.642-005-5

NBR 14432. Norma Brasileira Regulamentadora: Exigências de resistência ao fogo de elementos construtivos de edificações - Procedimento. 2000

SIA. Avaliação do risco de incêndio. Método de Cálculo. Tradução Alfredo Manuel F. Tovar de Lemos, Ildefonso Cabrita Neves. [s.I.:s.n.], 2004.

SCHUNIG. Fernando Raimundo. Políticas Públicas em Educação e Prevenção Contra Incêndio e Pânico: formulação de mecanismos de avaliação e controle. V Seminário Nacional Interdisciplinar em Experiências Educativas - Universidade Estadual do Oeste do Paraná, Francisco Beltrão, 2015. ISBN: 978-85-89441-66-7. 